\title{
Dissociated eye movements in craniosynostosis: a hypothesis revived
}

\author{
H Cheng, M A Burdon, G A Shun-Shin, S Czypionka
}

\begin{abstract}
A characteristic pattern of dissociated eye movements was observed in a large proportion of our patients with a variety of craniosynostosis syndromes. These anomalies simulate overaction of the inferior oblique and underaction of the superior oblique muscles which, however, cannot fully explain the abnormalities. In a number of cases, excyclorotation of the muscle cone was observed, with the upper pole of the eye tilted away from the midline. It is postulated that such excyclorotation of the eyes will lead to dissociated eye movements which can be explained on physiological grounds according to Hering's law. This paper presents a review of our patients and evidence to support this hypothesis.

(BrF Ophthalmol 1993; 77: 563-568)
\end{abstract}

The Radcliffe Infirmary, Oxford Eye Hospital,

Oxford

H Cheng

M A Burdon

G A Shun-Shin

$S$ Czypionka

Correspondence to:

Mr Hung Cheng, The

Radcliffe Infirmary, Oxford

Road, Oxford OX2 6HE.

Accepted for publication

29 April 1993
Figure 1 The case described showing the eyes in the primary position $(d)$, looking straight up and down $(c, e)$, and looking from side to side - fixing with the right eye $(a, g)$ and fixing with the left eye $(b, f)$ quently in our clinic. Coronal synostosis, characteristic of these patients, results in lack of bone growth in the anteroposterior direction and brachycephaly. Mid-facial hypoplasia and underdevelopment of the base of the skull lead to shallowing of the orbit and proptosis, while compensatory lateral expansion of the cranium predisposes to hypertelorism and orbital divergence.

The many ocular abnormalities that have been described $^{23}$ in this group of patients can be divided into three main groups: those involving the optic nerve, those due to proptosis or exposure, and motility abnormalities including squints, of which exotropia is common: Thus, Pruzansky $^{3}$ and $\mathrm{Choy}^{4}$ both reported a $50 \%$ prevalence, or more, of exophoria in patients with mid-face hypoplasia, and Morax ${ }^{5}$ reported that $89 \%$ had exotropia or vertical deviation. The ' $V$ ' syndrome was 'almost constant' in his reported cases, ascribed to overaction of one or both inferior oblique muscles. Other abnormalities reported are the absence of vertical recti or obliques. ${ }^{6-12}$

In the course of reviewing our patients, we have also observed the frequent occurrence of motility abnormalities which simulate over and underaction of the inferior and superior oblique muscles respectively, but which cannot be explained entirely by such an assumption. These dissociated movements have a pattern which is best illustrated by the detailed description of one case. 
Figure 2 Top, patient looked down to command. Bottom, patient followed a target, looking down, fixing with the left eye.
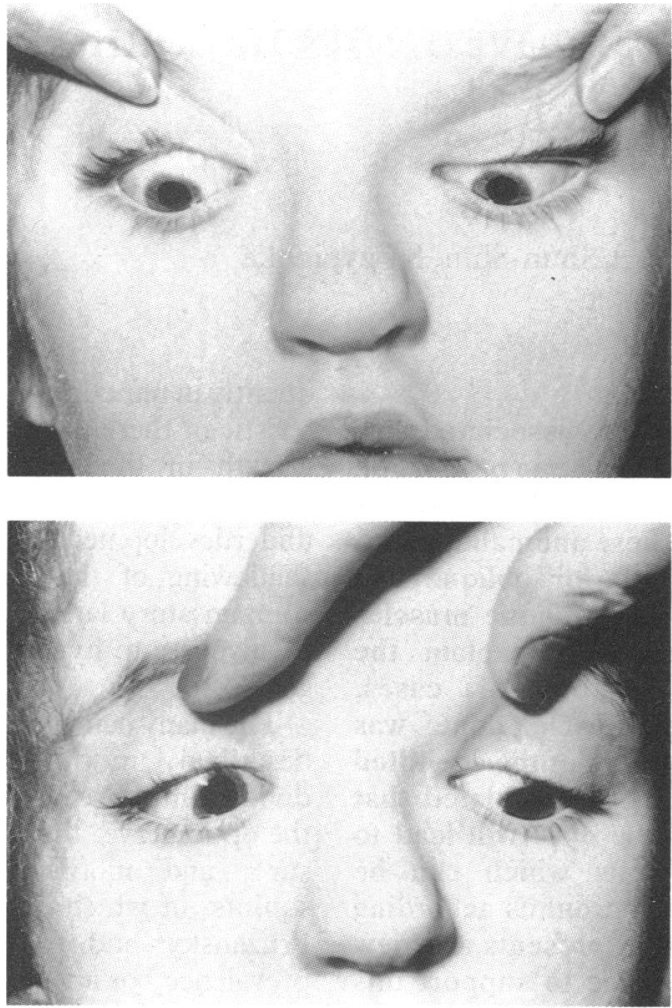

\section{CASE ILLUSTRATION}

An 8-year-old girl with craniofrontonasal dysplasia had a craniotomy and frontal advancement for coronal synostosis at the age of 5 months.

At the age of 5 years she had surgery to correct the hypertelorism; she had a divergent squint which changed to a small convergent squint after craniofacial surgery. There was considerable cosmetic improvement with relatively straight eyes in the primary position (Fig ld). However, if she looked to either side with the abducting eye fixing, the adducting eye became grossly elevated (Fig la, f). In making the same movement with the adducting eye fixing, the abducting eye is moved to a down and out position (Fig lb, g). Thus on performing a left to right pursuit movement, fixing with the left eye, the right moves from an up and in to a down and out position. In addition she had a marked ' $\mathrm{V}$ ' with the eyes diverging looking up and converging looking down (Fig 1c, e). However, if one eye was fixing looking down, the non-fixing eye would simply adduct with little or no depression of that eye (Fig 2).

The purpose of this paper is to advance a hypothesis to explain the dissociated movements.

Our hypothesis is based on the findings that excyclorotation of the contents of the orbit was shown to have occurred in a number of cases.

Table 1 Patients grouped by diagnosis and the type of deviation

\begin{tabular}{llllllll}
\hline Diagnosis & $\begin{array}{l}\text { Total no of } \\
\text { patients }\end{array}$ & $\begin{array}{l}\text { Mean age } \\
\text { (range) }\end{array}$ & $\begin{array}{l}\text { Manifest } \\
\text { eso }\end{array}$ & $\begin{array}{l}\text { Manifest } \\
\text { exo }\end{array}$ & $\begin{array}{l}\text { Manifest } \\
\text { vertical }\end{array}$ & Latent & $\begin{array}{l}\text { No } \\
\text { fixation }\end{array}$ \\
\hline Apert's & 24 & $9(1-18)$ & 12 & 7 & 1 & 3 & 1 \\
Crouzon's & 15 & $12(1-32)$ & 3 & 5 & 0 & 7 & 0 \\
Pfeiffer's & 5 & $6(4-8)$ & 0 & 4 & 0 & 1 & 0 \\
CFND/FND & 19 & $13(1-36)$ & $6^{\star}$ & 3 & 2 & 8 & 0
\end{tabular}

$\star$ Three were exotropic before correction of hyperelorism.

CFND=craniofrontonasal dysplasia.

$\mathrm{FND}=$ frontonasal dysplasia.
Excyclorotation, defined as the rotation of the upper pole of the globe away from the midline, would explain the pattern of dissociated movements simply by invoking Hering's law without the need of assuming over or underaction of certain muscles.

\section{Material and method}

We reviewed all the notes of patients in our clinic with the diagnosis of Crouzon's, Apert's, and Pfeiffer's syndrome, as well as those with craniofrontonasal and frontonasal dysplasia (CFND/ FND). Being one of four supraregional centres, our patients were referred from all parts of the British Isles. The patients have all had a full ophthalmic assessment, including orthoptic examination on presentation.

For geographical reasons patients were only followed if further attendance was needed for management of craniofacial problems, except for those living locally, or those able to gain access easily to the clinic.

The position of the eyes, the presence of squint, and the type of motility problems were recorded and, where possible, videotaped with consent from the parents.

$X$ rays or computed tomograms of the skull were obtained for all subjects. However, because of the postural requirements to obtain coronal sections of the orbits it was not possible to do this in very young patients. We obtained coronal sections in only one patient who was in her teens. Magnetic resonance imaging of the orbits was obtained in three patients, two of whom needed examination under anaesthesia, and the two tests were carried out at the same time under anaesthesia. The third patient was a cooperative adolescent.

Retinal photography was not routinely carried out and is difficult in young children, but we have photographed two of the older children.

Five patients have had squint surgery on cosmetic grounds at the request of the parents or guardians and provided actual anatomical details of the muscle insertions.

\section{Results}

Of the 63 patients seen, $68 \%$ had a manifest squint, while in one patient it was not possible to be certain because of the patient's age and debility (Table 1).

Fifty per cent of patients with Apert's syndrome had an esotropia, but those with Crouzon's and Pfeiffer's were mostly exotropic. There was a pattern of dissociated movements which have been described in detail above, which affected a large proportion of cases (Table 2).

This pattern was observed as a bilateral phenomenon in $50 \%$ or more of cases with Apert's and Pfeiffer's syndromes and CFND/ FND (53\%) but somewhat less in patients with Crouzon's syndrome (13\%). In the Apert's group, this feature was seen with equal frequency in cases with esotropia and exotropia.

In a proportion of patients, dissociated movements were only observed looking to one side, and in five patients the ocular movements were entirely normal (Table 2 ). 
Table 2 Patients grouped by diagnosis and the type of movement disorder

\begin{tabular}{|c|c|c|c|c|c|c|c|c|c|}
\hline Diagnosis & $\begin{array}{l}\text { Total } \\
\text { no seen }\end{array}$ & $\begin{array}{l}\text { Typical } \\
\text { dissociation } \\
\text { to both sides }\end{array}$ & $\begin{array}{l}\text { Upshoot/ } \\
\text { downshoot } \\
\text { to one side } \\
\text { only }\end{array}$ & $\begin{array}{l}\text { Upshoot of } \\
\text { adducting eye } \\
\text { or downshoot } \\
\text { of abducting } \\
\text { eye }\end{array}$ & $\begin{array}{l}\text { ' } V \text { ' with } \\
\text { dissociated } \\
\text { movements }\end{array}$ & $\begin{array}{l}' V ' \\
\text { only }\end{array}$ & $\begin{array}{l}\text { 'A' } \\
\text { pattern }\end{array}$ & $\begin{array}{l}\text { Random } \\
\text { movements } \\
\text { no fixation }\end{array}$ & Full \\
\hline $\begin{array}{l}\text { Apert's } \\
\text { Crouzon's } \\
\text { Pfeiffer's } \\
\text { CFND/FND }\end{array}$ & $\begin{array}{r}24 \\
15 \\
5 \\
19\end{array}$ & $\begin{array}{r}12 \\
2 \\
3 \\
10\end{array}$ & $\begin{array}{l}2 \\
3 \\
1 \\
0\end{array}$ & $\begin{array}{l}6 \\
8 \\
1 \\
4\end{array}$ & $\begin{array}{r}14 \\
7 \\
3 \\
7\end{array}$ & $\begin{array}{l}2 \\
0 \\
0 \\
1\end{array}$ & $\begin{array}{l}0 \\
1 \\
0 \\
1\end{array}$ & $\begin{array}{l}1 \\
0 \\
0 \\
0\end{array}$ & $\begin{array}{l}1 \\
1 \\
0 \\
3\end{array}$ \\
\hline
\end{tabular}

\section{IMAGING}

Four patients had magnetic resonance imaging of the orbit, such that coronal and horizontal views were reconstructed. Varying degrees of orbital deformation and excyclorotation of the extraocular muscles were demonstrated (Fig 3).

One teenage patient had a computed tomogram which also clearly showed excyclorotation of her extraocular muscles.

\section{FUNDUS DETAILS}

Two patients had fundus photographs, showing pseudo-ectopia of the fovea and excyclorotation of the retinal vessels (Fig 4). Additionally, two cases were recorded to have extorsion of vessels on clinical examination.

\section{SURGICAL FINDINGS}

Five patients came to cosmetic squint surgery, comprising two cases of Apert's, one of Crouzon's syndromes, and one each with craniofrontonasal and frontonasal dysplasia.

Of the three cases with Crouzon's syndrome and frontonasal dysplasia, all had excyclorotation of the horizontal recti. Two of them also had excyclorotated vertical recti with a more anterior insertion of the vertical muscles in one of them. The third case (Crouzon's) was said to have a missing inferior rectus and superior oblique muscle in the eye undergoing squint surgery, which was performed by a trained and accredited specialist. Subsequently, a magnetic resonance image showed both muscles to be present, but the inferior rectus was seen to be displaced medially (Fig 5). With dynamic reconstruction of the images, the entire course of the muscles could be traced well forward almost to the point of insertion.
Figure 3 Magnetic resonance image of the orbits of a patient showing considerable distortion of the shape of the orbit and marked exorotation of the extraocular muscles. The distortion of the orbits is asymmetrical.

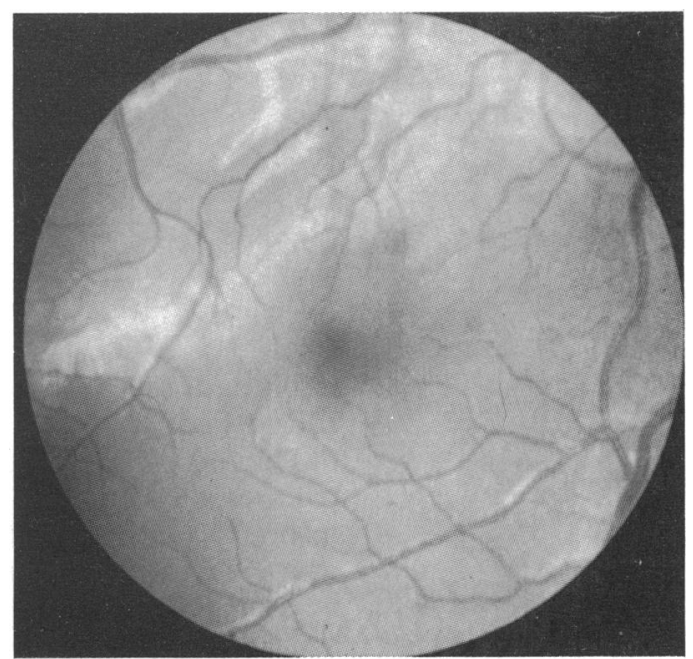

Figure 4 Fundus photograph of the right eye showing marked exorotation of the eye, illustrated by the rotated retinal vessels.

One of the cases of Apert's syndrome was reported to have normal muscle insertions, but the rotation was not looked for specifically. Her problem was ptosis and convergent squint and both eyes were recorded as having marked upshoots on adduction.

\section{Discussion}

Our findings suggest that excyclorotation of the orbital contents occurs not uncommonly in craniosynostosis with hypertelorism. Our hypothesis is that excyclorotation, causing malalignment of the axes of movement, will

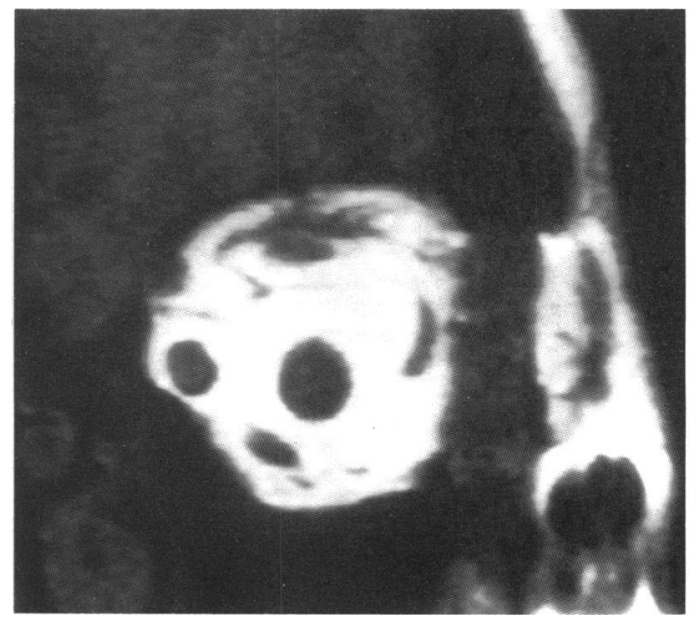

Figure 5 Postoperative magnetic resonance image of a case of Crouzon's syndrome reported at squint surgery to have missing inferior rectus $(I R)$ and superior oblique (SO) muscles. Note that both muscles are present but the IR is displaced nasally. 

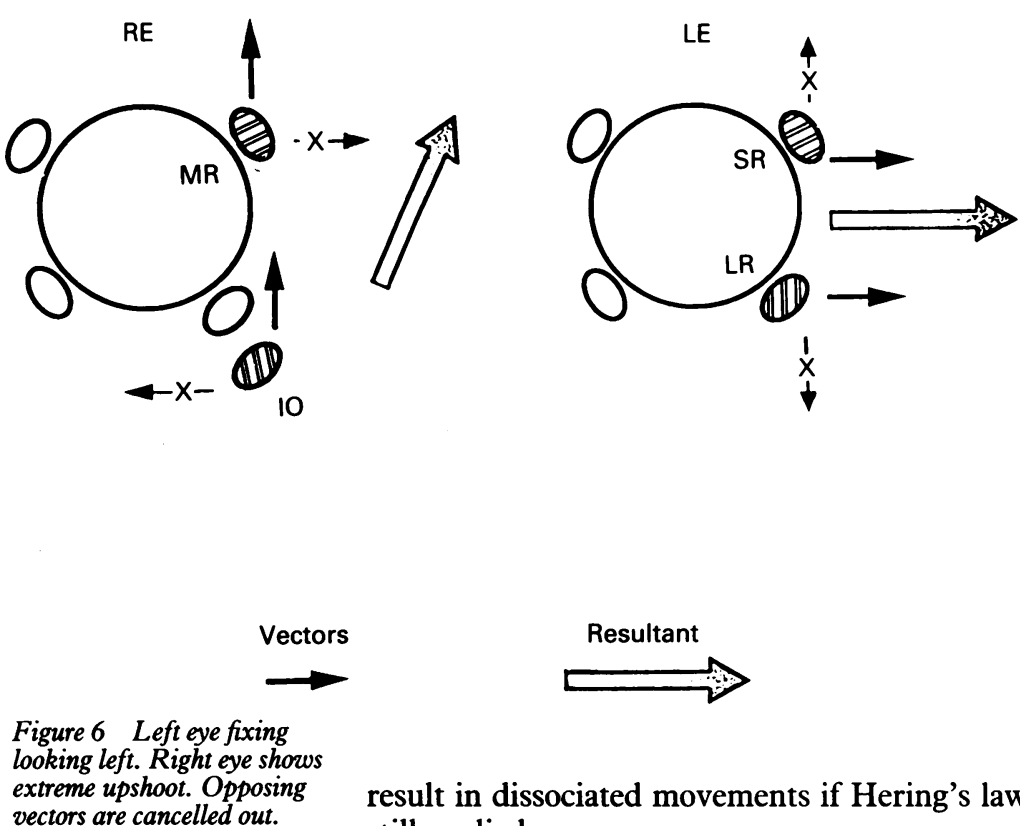

Figure 7 Right eye fixing looking left. Left eye is down and out.

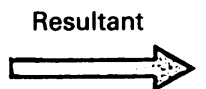

result in dissociated movements if Hering's law still applied.
Thus excyclorotation through 45 degrees requires the combined action of the superior rectus (SR) and lateral rectus (LR) for abduction, whose contralateral synergists are the opposite inferior oblique (IO) and medial rectus (MR) respectively (Fig 6). By using the same argument, on looking left with the right eye fixing, adduction is the resultant action of the right $M R$ and inferior rectus (IR), whose contralateral synergists will be the left $L R$ and superior oblique (SO), which in abduction will have very little vertical action (Fig 7); the result is a left eye in the down and out position. The adduction of the non-fixing eye when the other eye is following an object looking down, is not explicable by postulating SO underaction or using any other explanation, bearing in mind that both eyes can depress on looking down when executing a voluntary movement (Fig 2). When fixing on an object, the excyclorotated left eye is depressed by
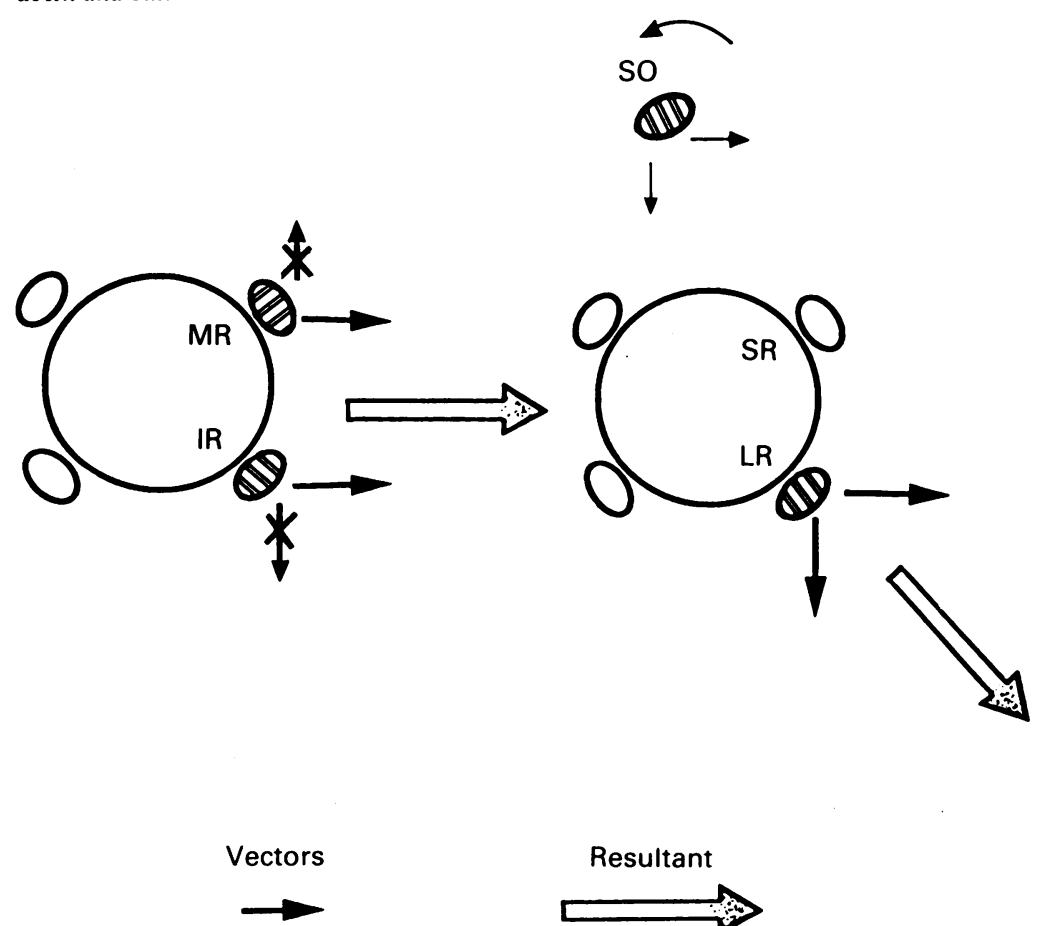

the combined action of the IR and LR whose contralateral synergists are the SO and MR respectively. The MR in the excyclorotated position will have both adducting and elevating actions. The elevation will be opposed by the depressing action of the SO which in an adducted position will have no significant abducting role. Thus the 'resultant' produces adduction of the non-fixing eye (Fig 8). If it was a superior oblique palsy alone and if the eye were not excyclorotated, depression of the left fixing eye should not result in adduction with little or no depression of the non-fixing right eye. On voluntary up and down gaze, the prime movers are the superior and inferior recti, hence both eyes move relatively symmetrically albeit with an exaggerated ' $V$ ' pattern owing to the displacement of the muscles (Fig 9).

EVIDENCE IN SUPPORT OF THE HYPOTHESIS

The anatomical evidence comes from:

1 imaging the excyclorotation of the extraocular muscles in five patients with anomalous eye movements;

2 four patients who were found to have excyclorotation of the insertions of the muscles at surgery;

3 in two patients, fundus photography was available to show the excyclorotation of fundus details with pseudo-ectopia of the macula (Fig 4). In two patients retinal vessels were recorded to be excyclorotated on ophthalmoscopy where photography was not obtainable.

An abnormal head posture was not a feature of these patients nor, indeed, was it a characteristic of the group. In the patient with demonstrable rotation of retinal vessels there was no apparent attempt to compensate for the rotation by head tilting even when fixing, which implies an adaptation at the cortical level.

Using physiological principles and invoking Hering's law, the anomalous pattern of eye movements can be explained by the excyclorotation of the globe and its extraocular muscles. Without this model of excyclorotation, we would need to postulate over or underaction of certain muscles, especially the obliques. While our hypothesis explains the observations, it does not exclude the possibility that the obliques may be over and underacting in certain instances: nor can one ignore the reports of missing muscles. While there are postulates for the overaction of the obliques, ${ }^{1314}$ and one accepts overaction of inferior obliques as a common phenomenon, there is no concrete evidence, such as electromyography, to support the hypothesis. Histological abnormality of the muscles as a cause of the anomaly must also be allowed for, since there is one report of structural abnormalities in Apert's syndrome. ${ }^{15}$ However, this is unlikely to be an important factor for the group as a whole since Crouzon's syndrome and craniofrontonasal dysplasia are not normally associated with soft tissue abnormalities. Another enigma is the absence of ptosis in cases where the SR were reported to be missing. ${ }^{679}$ Since the levator palpebrae superioris is derived embryologically from the $S R,{ }^{16}$ the latter's absence will require a postulate of secondary atrophy after the levator 

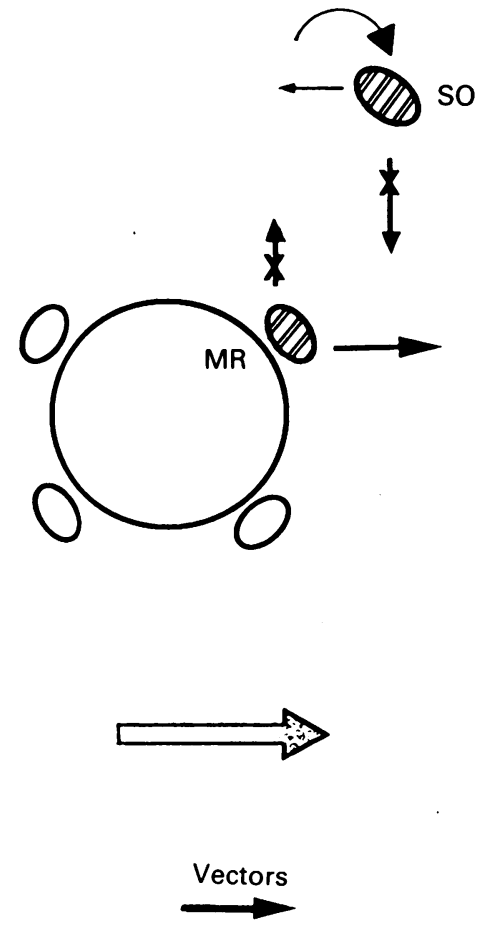

Figure 8 Left eye fixing looking down. The nonfixing right eye is adducted. The vertical actions have cancelled out.

Figure 9 Looking up and down to command, showing an exaggerated ' $V$ '.
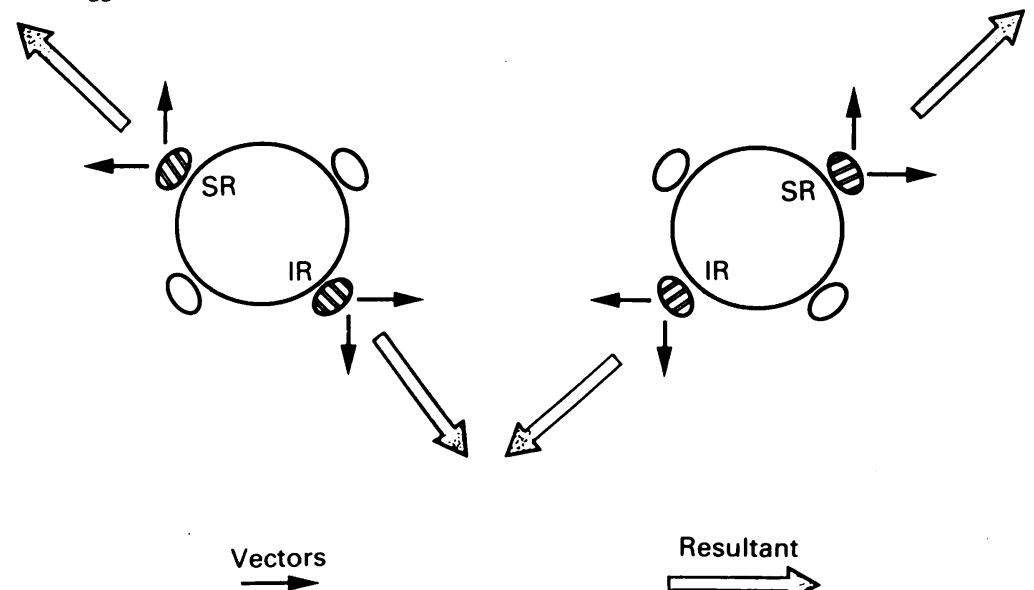

of the non-fixing eye when the other eye fixes on an object looking down (Fig 2).

The theory of sagittalisation ${ }^{17}$ has been advanced to explain some aspects of the ' $A$ ' and ' $V$ ' phenomenon though there is no proof that this is the underlying mechanism in cases that have no craniofacial abnormality. This theory postulates that the two obliques may be inserted into the globe at different angles to the sagittal plane. If the IO was inserted at a smaller angle than the SO, the torsional imbalance, through compensatory action of other muscles, would lead to the ' $V$ ' phenomenon. In most of our cases the mid-facial hypoplasia would result in the opposite shift of the IO, which could be expected to arise more posteriorly than the tendon of the SO, thus making a larger angle with the sagittal plane and would have the opposite effect. Another distorting possibility is the alteration of the direction of vectors by displacement of the fulcrum through contact between the rim of the orbit and the inferior rectus muscle. ${ }^{18}$ As Morax pointed out, this theory is inadequate, as the ' $V$ ' syndrome is unchanged after surgery, and the anomalies can be seen in 'teleorbitism without exorbitism'.

If excyclorotation of the orbital contents would lead to a ' $V$ ' on elevation, then the opposite would lead to an 'A' syndrome. Though such instances are rare, one case has been described where the muscles were shown on computed tomography to be incyclorotated ${ }^{19}$ and this finding complements our hypothesis.

While there is awareness of excyclorotation of the globe in craniosynostosis ${ }^{5}$ the pattern of dissociation that we have described has not been sufficiently emphasised, nor the fact that the pattern can only be fully appreciated by performing the same movements with the two eyes fixing alternatively. Previously, overaction of the inferior oblique, with or without underaction of the superior oblique, was frequently used as an explanation. While this possibility remains, we have shown that in cases where the excyclorotation is marked, the dissociated movements can be explained simply by applying Hering's law of equal innervation.

We are indebted to Dr P Anslow, Dr G Ashworth, Mr L Benjamin, Mr J Elston, and Mr M D Poole for help with the preparation of this paper, Mrs P Lewis for orthoptic assessment, and Mrs A S Gray for typing the manuscript.

1 Cohen MM, Craniosynostosis. Diagnosis, evaluation and management. New York: Raven Press, 1986; 13: 413.

2 Fries PD, Katowitz JA. Congenital craniofacial anomalies of ophthalmic importance. Surv Ophthalmol 1990; 35: 87-119.

3 Pruzansky S, Miller MT. Ocular defects in craniofacial syndromes. In: Rennie WA, ed. Goldberg's genetic and metabolic eye disease. Boston: Little, Brown, 1986;9: 241-55.

4 Choy AE, Margolis S, Breinin GM, McCarthy JG. Analysis of the pre-operative and post-operative extraocular muscle the pre-operative and post-operative extraocular muscle verse JM, et al. eds. The symposium on diagnosis and treatment verse JM, et al. eds. The symposium on diagnosis and trea
of craniofacial anomalies. St Louis: Mosby, 1979: 128 .

5 Morax S. Oculo-motor disorders in craniofacial malformations. $\mathcal{F}$ Max-fac Surg 1984; $12: 1-10$.

6 Diamond GR, Katowitz JA, Whitaker LA, Quinn GE Schaffer DB. Variations in extraocular muscle number and structure in craniofacial dysostosis. Br $\mathcal{F}$ Ophthalmol 1980 64: 416-8

7 Weinstock EJ, Hardesty HH. Absence of superior recti in craniofacial dysostosis. Arch Ophthalmol 1965; 74: 152-83.

8 Snir M, Gilad E, Ben-Sira I. An unusual extraocular muscle anomaly in a patient with Crouzon's disease. $\mathrm{Br} \mathcal{F}$ Ophthalmol 1982; 66: 253-7.

9 Cuttone J, Brazis P, Miller M, Folk S. Absence of the superior rectus muscle in Apert's syndrome. F Pediatr Ophthalmol Strabismus 1979; 16: 349. 
10 Walker JW, Russell-Eggitt I, Taylor D. Ocular motility problems in craniofacial dysostosis. In: Kaufmann II, ed. problems in craniofacial dysostosis. In: Kaufmann 11, ed. Trans $18 \mathrm{ch}$

11 Lee JP. Congenital muscular defects. Eye 1992; 6: 181-3.

12 Pollard Z. Bilateral superior oblique muscle palsy associated with Apert's syndrome. Am $\mathcal{F}$ Ophthalmol 1988; 106 : 337-40.

13 Urrets-Zavalia A, Jr. Significance of congenital cyclovertical motor defects of the eyes. Brf Ophthalmol 1955; 39 : 11.

14 Urrets-Zavalia A. Reaction to dissociations and primary insufficiencies of the vertical acting muscles: a discussion of the pathogenesis of the A+V syndromes. Trans Am Acad Ophthalmol Otolaryngol 1981: 324.
15 Margolis S, Pachter BR, Breinin GM. Structural alterations of extraocular muscle associated with Apert's syndrome. Br fOphthalmol 1977; 61: 683-9.

16 Mann IG. Development of the human eye. 2nd ed. London: Mann IG. Develc

17 Gobin MH. Sagittalisation of the oblique muscles as a possible cause for the ' $A$ ', ' $V$ ' and ' $X$ ' phenomena. Br $\mathcal{F}$ Ophthalmol $1968 ; 52: 13-8$.

18 Ortiz-Monasterio F, Fuente del Campo A, Limon-Brown E. Mechanism and correction of $\mathrm{V}$ syndrome in craniofacial dysostosis. Symposium on plastic surgery in the orbital region. St Louis: Mosby, 1976: 247-54.

19 Millar JE, Gado H. Computerised axial tomography in strabismus patients. In: Ravault AP, Lenk M, eds. Trans Fifth Int Orthoptic Congress. France: LIPS, 1983: 393-400.

\section{History of ophthalmology}

\section{The invention of spectacles}

The benefits of viewing the world through glass have long been recognised, and the fact that the emperor Nero invariably watched the gladiators' events through a large emerald held to his eye is often quoted as an example. There are, however, several explanations for this, none of which include the principles of optics. Firstly, it was rumoured that Nero disliked the colour of blood (of which there was always plenty), and secondly, he loved to show off his wealth. Possibly he was using his emerald as sunglasses against the glare but, sadly, it never occurred to him to have it attached to a frame as a primitive pair of spectacles. Myopia was certainly recognised in his time, with short sighted slaves being sold at a discount. It is recorded that Dionysius in $460 \mathrm{BC}$, was myopic, and that his terrified courtiers (he was a tyrant) all feigned the same affliction in order to pacify him.

The credit for securing lenses in front of the eye may go to the Chinese, who were apparently seen by Marco Polo in 1270 to be sporting framed lenses attached to the head by weighted cords hanging over the ears. In Britain, it was left to Roger Bacon to moot the concept of 'using glass lenses to aid those who are old and have weak sight' (his own words). The Italians would disagree, and give the credit to Armati, who died in 1317 , largely because his tombstone bears the inscription 'the inventor of spectacles.'

Religious paintings of the fifteenth century show St Hieronymous and St Donatus availing themselves of the devices, and apparently the church saw nothing heretical in their use. It certainly condoned them in 1623 when de Valdez (who happened to be an officer of the inquisition) published a superb monograph on their use at that time.

De Valdez reports that the 'refractionists' of his day did brisk trade, and began by asking the patient's age. As a rule of thumb, a man between 30 and 40 would require glasses of two varas (the vara approximates to one dioptre), a woman would get a stronger lens. The 'optician' would then inquire - if it were not obvious from the customer's dress and demeanour - whether leather, brass, silver, or gold frames were required. Common sense was present in the $1600 \mathrm{~s}$, as the optician would warn that glasses were not a 'cure-all,' and that a lens that was too weak was better than one that was too strong. 'Opera glasses' that were held for short periods of distant vision were available, and glasses to protect from the 'winds of winter and bright lights of summer' came in yellow, brown, red, green, and blue.

De Valdez touches upon the debate about noseglasses versus earframes, etc. King Philip had his glasses set into 'temple pieces' which attached to his hat and steadied the spectacles on the royal nose, but de Valdez notes this is impossible for the common man, who needs to be continually removing his hat from politeness.

Although glasses were ridiculed at certain times in history, snobbery reared its ugly head in England in the 1700s. Then the gentry purchased glasses as a sign of intelligence and refinement, whether they needed them or not, but the lower classes - however much they stumbled into doors and dropped things - did not dare wear them in public. This was just as well, since they couldn't have afforded them anyway. Until the seventeenth century spectacles were so valuable as to be separately bequeathed in one's will, presumably regardless of the visual acuity of one's beneficiaries.

FIONA ROMAN

Oliver GH. The history of the invention and discovery of spectacles. London: BMA, 1913.

Sorsby A. A short history of ophthalmology. London: Staples Press, 1948: 68-76.

Ten Doesschate G. Some historical notes on spectacles and beryllus. Br f Ophthalmol 1946; 30: 660-2.

Wood CA. The first scientific work on spectacles. In: Packard FR ed. Annals of medical history. London: Hoeber, 1940; 2: 150-5. 